\title{
MENGKAJI HAKEKAT MISI INKLUSIF YESUS BERDASARKAN INJIL LUKAS DAN APLIKASINYA BAGI MISI MASA KINI
}

\author{
Yesri Talan \\ Sekolah Tinggi Teologi Sabda Agung, Surabaya \\ yesritalan@gmail.com
}

\begin{abstract}
Luke introduces Jesus' inclusive ministry to preach the gospel, fellowship and serve the excluded. In this context, people who are paralyzed, blind, deaf, poor, tax collectors who are considered sinful, they are the center of His attention. By observing the current mission which is oriented to the church planting mission, it is necessary to transform. The intended transformation is to change the motive of the church planting mission to a mission that is not an anthropocentric mission but a mission to glorify God. The method used in writing this scientific paper is a qualitative method. Literature study and the Bible as the main source in explaining. Aside from literature and Bible study sources, the sources obtained are based on facts from field observations.
\end{abstract}

Keywords: $\quad$ Mission, Inclusive, Today's.

Abstraksi: $\quad$ Lukas memperkenalkan pelayanan Yesus secara inklusif yaitu memberitakan Injil, bersekutu dan melayani yang kaum marjinal. Dalam konteks ini, orang lumpuh, buta, tuli, miskin, pemungut cukai yang dianggap berdosa, merekalah yang menjadi pusat perhatian-Nya. Dengan mengamati misi sekarang ini yang berorientasi pada misi penanaman gereja maka perlu adanya transformasi. Transformasi yang dimaksudkan adalah merubah motifasi misi penanaman gereja menjadi misio dei sehingga misi yang dilakukan bukan bersifat antroposentris melainkan misi untuk memuliakan Tuhan. Metode yang dipakai dalam penulisan karya ilmiah ini adalah metode kualitatif. Kajian pustaka serta Alkitab sebagai sumber utama dalam menjelaskan. Selain dari sumber kajian pustaka dan Alkitab, sumber yang diperoleh adalah berdasarkan fakta observasi di lapangan.

Kata Kunci: Misi, Inklusif, Masa Kini.

\section{PENDAHULUAN}

Misiologi adalah pusat dari pemberitaan kerajaan Allah yang diberitakan

Oleh Yesus ketika Ia ada dalam dunia (Lukas 10: 9, 10: 11, 19: 11, 21: 31). Istilah

misi berasal dari bahasa Latin Misio yang diangkat dari kata dasar mittere yang berkaitan dengan kata Misum yang berarti to send (mengirim atau mengutus).

Dalam bahasa Yunani kata misi berasal dari kata apostello yang berarti mengirim 
atau mengutus dengan kuasa. ${ }^{1}$ Demikian pula dengan pernyataan I Nyoman Enos menuliskan arti misiologi berasal dari dua kata dalam bahasa Latin yaitu Misio yang berarti mengutus dan logos yang berarti studi kata atau ilmu. Jadi misiologi berarti ilmu yang mempelajari tentang pengutusan atau pengiriman orang oleh gereja. ${ }^{2}$ Dengan demikian misi adalah ilmu tentang mengutus dan mengirim orang untuk menyampaikan Kabar Baik. Dalam konteks ini mengirim atau mengutus orang untuk memberitakan kabar sukacita kepada orang-orang yang belum mengenal siapa Yesus.

Sebagai contoh pelaksana dari arti misi agung yang telah diuraikan di atas dapat diamati dalam Pelayanan Yesus. Yesus menjadikan Kerajaan Allah sebagai berita sentral bagi semua umat manusia. Bagus Surjantoro, menanggapi pernyataan ini dengan mengungkapkan bahwa, Yesus sangat serius dengan misi karena misi adalah isi hati Bapa kepada dunia ini. ${ }^{3}$ Misi Yesus ini dinyatakan dalam Alkitab sebagai berita yang utama ketika manusia jatuh dalam dosa. Misi ini digenapi di dalam karya penyelamatan Kristus sebagai bukti penggenapan misio Dei.

Relevansi misi dalam dunia teologi haruslah dipandang sebagai sesuatu yang esensi. Dalam hal ini apabila mengkaji ilmu teologi maka yang menjadi acuan dasar dalam berteologi adalah misiologi. Sebab misiologi adalah pusat pernyataan Allah kepada dunia ini. Hal senada diungkapkan oleh Marthin Kahler bahwa, misiologi haruslah menjadi pusat perhatian dari teologi atau misi adalah induk teologi. ${ }^{4}$ Pernyataan Kahler memberikan sebuah paradigma baru dalam

\footnotetext{
1 Yakub Tomatala, Teologi Misi (Jakarta: Leadership Foundation, 2003), 16.

2 I Nyoman Enos, Penuntun Praktis Misiologi Modern (Bandung: Kalam Hidup, 2003), 11.

3 Bagus Surtjantoro, Misi Dari Dalam Krisis (Jakarta: Obor Mitra Indonesia, 2003$), 2$.

4 David J. Bosch, Transformasi Misi Kristen (Jakarta: BPK Gunung Mulia, 2008), 22.
} 
dunia teologia bahwa orientasi dari seluruh teologi seharusnya dimulai dari misiologi. Pernyatataan ini secara akademis mengandung nilai teologia yang sangat bermanfaat bagi misi masa kini bahwa seluruh upaya manusia dalam melakukan misi seharusnya berpusat pada misio Dei. Pemahaman tentang misio Dei sebagai Kabar Baik yang perlu disampaikan kepada manusia bahwa Allah adalah satu-satunya Tuhan bagi manusia. Sehingga Kabar Baik ini perlu untuk disampaikan sebagai kabar sukacita untuk manusia.

Misi dipahami sebagai jawaban Allah bagi manusia yang telah jatuh dalam dosa. David J. Bosch juga sependapat dengan pernyataan tersebut bahwa, misi adalah jawaban 'ya' Allah kepada dunia. 5awaban 'ya' yang dimaksudkan David J. Bosch artinya misi adalah wujud kasih Allah kepada dunia yang berdosa. Manusia yang diciptakan seturut dengan gambar-Nya tidak mampu untuk mengemban tugasnya sebagai wakil Allah dan jatuh dalam dosa maka jalan yang ditentukan Allah untuk mengembalikan manusia kepada gambar yang semula adalah melalui misio Dei yang digenapi di dalam Kristus.

Misi Yesus merupakan misi yang telah ditentukan oleh Allah sebagai sesuatu yang esensial. Misi ini mencakup keselamatan yang disampaikan oleh Yesus ketika Ia ada dalam dunia agar setiap orang yang mendengarkan berita tersebut menjadi percaya dan diselamatkan. Setelah Yesus menjalankan misi-Nya di dunia maka berita ini diteruskan kepada murid-murid-Nya sebagai prinsip dasar yang harus dilakukan sebagai seorang murid. Sebelum Yesus kembali ke Surga, Ia berpesan kepada murid-murid-Nya agar mereka pergi dan menjadikan semua bangsa menjadi murid-Nya (Mat. 28: 19). Pesan ini menjadi filosofi dasar gereja 
masa kini dalam membangun paradigma misi sehingga kerangka berpikir gereja untuk misi masa kini adalah mengutus murid dengan tugas memenangkan jiwa.

Apabila menganalisis metode misi masa kini berdasarkan Injil Matius 28: 19-20 paradigma misi sudah berubah esensinya dari misio Dei kepada misi anthroposentris. Verkuyl mengungkapkan bahwa misi sekarang sudah tercemar dengan motivasi-motivasi yang salah yaitu motif imperialisme, motif budaya dan motif romantik. ${ }^{6}$ Motif-motif ini menjadi dorongan utama dalam menjalankan misi. Motif imperialisme dikenal sebagai misi yang menjadikan orang-orang yang dilayani sebagai kawula yang patuh. Motif ini secara langsung bersifat kolonialisme sehingga orang-orang yang dilayani bukan untuk memenuhi misio Dei tetapi untuk kepentingan dirinya. Selain motif imperialisme, motif budaya juga merupakan sebuah motif yang bersifat anthroposentris karena motif ini menggunakan segala upaya untuk menjadikan budaya misionaris yang lebih unggul.

Dalam hal ini budaya yang ditemukan di ladang misi ditranformasikan agar sesuai dengan nilai-nilai Injil. Apabila mengkaji metode ini memang tidak salah dan sepatutnya misi yang dilakukan seharusnya mencakup hal tersebut. Namun yang menjadi problem adalah apakah dengan metode ini proses pemberitaan Injil berhasil disampaikan dan membawa jiwa-jiwa dimenangkan untuk Tuhan. Inilah problem yang terus menerus menjadi masalah yang fundamental dalam pelayanan misi. Apalagi budaya yang dianut sudah bertahuntahun menjadi tradisi yang turun menurun maka budaya misi yang digunakan untuk mengubah budaya lokal sangatlah tidak mudah.

${ }^{6}$ Bosch, 7. 
Selain beberapa motivasi di atas yang menjadi acuan dasar dalam misi modern, motivasi penanaman gereja juga menjadi motivasi yang selalu digunakan dalam misi sekarang. Peter Wagner dalam bukunya yang berjudul Penanaman Gereja Untuk Tuaian Yang Lebih Besar, mengungkapkan bahwa gereja-gereja yang bertumbuh adalah gereja yang menekankan penanaman gereja dalam menjalankan misi. ${ }^{7}$ Lebih lanjut Peter Wagner memberikan contoh gereja yang bertumbuh dengan pesat hasil dari misi adalah gereja Assemblies of God. Pada tahun 1990-an gereja Assemblies of God menuai satu juta mitra doa, memenangkan lima juta orang bagi Kristus, melatih dan memuridkan dua puluh ribu orang dan mendirikan lima ribu gereja. ${ }^{8}$

Hal yang senada pun diungkapkan oleh Yakob Tomatala, dengan mendefinisikan misi dengan kata Mision yang secara praksis berhubungan dengan persekutuan, penyembahan dan pelayanan umat Allah. Berkaitan dengan definisi tersebut maka misi dipahami sebagai memberitakan Yesus dalam kuasa Roh Kudus kepada orang berdosa yang disampaikan dengan penuh keyakinan agar orang berdosa tersebut bertobat dan menerima Yesus sebagai Tuhan dan Juruselamat dan menjadi anggota baru dalam gereja. ${ }^{9}$

Sebuah artikel misi menjelaskan bahwa, untuk dapat bertumbuh secara kuantitas, gereja perlu mempunyai pelayanan penginjilan yang menjangkau ke luar. ${ }^{10}$ Dengan mengamati beberapa pendapat para ahli di atas maka dapat dipahami bahwa misi sekarang beralih dari misio Dei kepada misi yang bersifat

7 Peter Wagner, Penanaman Gereja Untuk Tuaian Yang Lebih Besar (Jakarta: Harvest Publication House, 1995), 16.

8 Wagner, 17.

${ }^{9}$ Tomatala, Teologi Misi, 19.

${ }^{10}$ N N, "Kunci Bagi Pertumbuhan Gereja Sesudah Dirintis," www.misi.sabda.org, E-Misi, diakses 15 Februari 2020, https://misi.sabda.org/enam_kunci_bagi_pertumbuhan_gereja_sesudah_dirintis. 
anthroposentris. Misi sekarang lebih mengutamakan bagaimana jiwa dimenangkan untuk pertumbuhan gereja sehingga orientasi misi bergeser dari esensinya menjadi misi untuk penanaman gereja.

Memang benar bahwa misi untuk penanaman gereja berhasil dalam hal memenangkan jiwa, namun motivasi misi penanaman gereja bisa bersifat negatif karena tujuan daripada misi ini adalah untuk kepentingan pribadi atau misi anthroposentris. Seperti yang diungkapkan Verkuyl bahwa motivasi misi penanaman gereja adalah untuk menjadikan jiwa-jiwa yang dimenangkan sebagai kawula yang taat. Misi yang dijalankan bersifat kolonialisme untuk kepentingan diri sendiri. ${ }^{11}$ Misi sekarang adalah misi untuk penanaman gereja. Karena banyak perintisan yang berorientasi pada pertumbuhan gereja maka salah satu hal yang dapat dilakukan sebagai fondasi dalam pelayanan adalah misi untuk penanaman gereja.

Berdasarkan uraian latar belakang masalah di atas maka tujuan penelitian ini dilakukan untuk mengkaji bagaimana hakekat misi inklusif Yesus dalam konteks Injil Lukas sebagai acuan bagi tranformasi misi masa kini. Penelitian ini penting untuk dilakukan karena misi gereja masa kini sudah beralih dari esensi misi Allah kepada misi untuk kepentingan gereja. Masalah misi masa kini menjadi masalah yang signifikan, oleh karena itu penting untuk mengkaji dan memahami bagaimana metode pelayanan misi Yesus dalam Injil Lukas sehingga metode yang dipakai menjadi standar motivasi dalam pelayanan misi masa kini.

11 Bosch, Transformasi Misi Kristen, 7. 


\section{METODOLOGI}

Metode yang dipakai dalam penulisan karya ilmiah ini adalah metode kualitatif. Merode ini akan melakukan kajian pustaka. Sumber pustaka utama yang digunakan adalah Alkitab didukung dengan buku-buku Teologi yang berkaitan misi serta Jurnal Teologi yang membahas tentang misi. Selain dari sumber kajian pustaka, data penulisan artikel ini diperoleh berdasarkan fakta observasi di lapangan.

\section{HASIL}

Lukas memperkenalkan misi Yesus sebagai misi yang inklusif. Misi yang tidak melihat status dan golongan, orientasi pelayanan-Nya adalah memberitakan Injil kepada mereka yang tersisihkan dan yang dianggap berdosa untuk memperoleh keselamatan. Tujuan dari misi Yesus adalah membawa jiwa-jiwa yang terabaikan untuk memperoleh keselamatan bukan untuk penanaman gereja. Dengan menganalisis misi Yesus dalam Injil Lukas maka misi sekarang perlu untuk ditransformasikan. Dalam hal ini, motifasi penanaman gereja untuk pertumbuhan secara kuantitas perlu untuk diperbaharui sehingga esensi daripada misi gereja untuk kemuliaan Tuhan.

\section{PEMBAHASAN}

Dalam pembahasan ini akan diuraikan tentang hakekat misi Yesus dalam Injil Lukas yang bersifat marturia, koinonia, diakonia dan aplikasi misi Yesus dalam konteks misi masa kini.

\section{Hakekat Misi Yesus Dalam Injil Lukas}

Misi menjadi isu yang sentral dalam pelayanan Yesus secara kusus dalam Injil Sinoptik. Dalam Injil Lukas secara eksplisit Yesus diperkenalkan sebagai 
hamba Allah yang melayani. Hal ini terbukti dalam keseluruhan pasal Injil Lukas hanya berbicara tentang satu hal yaitu tentang misi Yesus sebagai hamba Allah yang diutus.

Misio Dei menjadi pusat perhatian utama selama pelayanan Yesus di bumi. Misi Yesus dikenal sebagai misi yang inklusif, misi yang tidak membedakan baik golongan maupun status, miskin, kaya, buta, tuli, lumpuh, pemungut cukai, orang-orang tidak terpelajar menjadi pusat perhatian-Nya. Kaum marjinal dalam konteks pelayanan Yesus menjadi pusat perhatian-Nya. Dengan demikian dasar misi dalam Injil Lukas bersifat Kristosentris bukan bersifat kontekstual. Kristus yang menjadi pusat perhatian Lukas dalam menuliskan Injilnya, bukan budaya atau tradisi yang menjadi objek perhatian. Maka misi inklusif Yesus dalam Injil Lukas dapat diuraikan sebagai berikut:

\section{Misi Yesus Bersifat Marturia}

Kata marturia berasal dari bahasa Yunani yang berarti bersaksi atau menceritakan kabar baik bahwa Allah mengasihi semua manusia dan telah mengutus Yesus ke dalam dunia untuk menjalankan misi Allah. ${ }^{12}$ I Nyoman menyebutkan bahwa dalam Injil Lukas ada dua pokok utama dalam misi Yesus yang bersifat marturia yaitu: Pertama adalah pengajaran Yesus tentang kerajaan Allah. ${ }^{13}$ Kristus menjadikan pelayanan-Nya sebagai upaya untuk menghadirkan kerajaan Allah di muka bumi ini.

Hal ini dilukiskan oleh Lukas dalam Injilnya mulai dari pasal satu. Lukas menyusun secara sistematis Injilnya dengan menampilkan Yohanes pembaptis sebagai perintis jalan bagi pemberitaan tentang kerajaan Allah. Lukas 
memperkenalkan Yohanes pembaptis sebagai suara yang berseru-seru di Padang Gurun untuk mempersiapkan jalan dalam rangka menerima kerajaan Allah. ${ }^{14}$ Yohanes memulai pelayanannya dengan menyerukan pertobatan bagi orangorang agar bertobat sebab kerajaan Allah yang akan dinyatakan oleh Yesus sudah dekat.

Setelah Yohanes mempersiapkan jalan bagi Kerajaan Allah maka Yesus memulai pelayanan-Nya. Ia dibaptis sebagai materai dari Allah bahwa Dialah yang diutus untuk menjalankan misi tersebut. Ketika menganalisis Injil Lukas dari perspektif misiologi maka misi Yesus pertama kali dilakukan kepada muridmurid-Nya. Simon Petrus, Yakobus dan Yohanes yang adalah penjala ikan menyerahkan diri menjadi murid. Setelah mereka melihat peristiwa penangkapan ikan yang luar biasa banyaknya. Peristiwa tersebut menjadi titik tolak dari perubahan hidup Simon Petrus beserta dengan anak-anak Zebedeus. Misi yang Yesus lakukan terhadap mereka adalah misi yang bersifat marturia.

Sama halnya dengan pertobatan Lewi pemungut cukai, setelah Yesus menyembuhkan banyak orang yang sakit lumpuh, Ia keluar dan menjumpai Lewi duduk di rumah cukai sedang melakukan tugasnya. Yesus berkata kepadanya ikutlah Aku. Dan Lewi pun meninggalkan segala sesuatu lalu mengikuti Dia. Dengan demikian dapat dipahami bahwa pelayanan Yohanes dan Yesus secara ekplisit menunjukan bahwa misi yang diperkenalkan dalam Injil Lukas adalah misi yang bersifat marturia. Yaitu bersaksi tentang kabar sukacita bahwa Allah mengasihi dunia ini dan telah mengaruniakan Anak-Nya untuk menebus manusia. Hal senada juga diungkapkan oleh I Nyoman Enos bahwa setral dari misi dalam

14 B.J Boland, Tafsiran Lukas (Jakarta: BPK Gunung Mulia, 1970), 73-74. 
Injil Lukas adalah memberitakan tentang Injil kerajaan Allah dengan motivasi mencari dan menyelamatkan yang hilang. ${ }^{15}$ Berita inilah yang menjadi pusat pelayanan Yesus kemanapun Ia pergi.

Kedua adalah pemberitaan kematian-Nya. Setelah memperkenalkan berita tentang kerajaan Allah sebagai pusat misi maka Yesus juga menyampaikan tentang berita kematian-Nya sebagai esensi dari misi-Nya. Pada malam paskah Yesus berkata kepada murid-murid-Nya bahwa, Ia sangat rindu makan paskah bersama-sama dengan mereka sebelum Ia menderita. Sebab Ia tidak akan makan lagi bersama-sama sampai beroleh kegenapan dalam kerajaan Allah (Luk. 22: 16).

Berita tersebut sebagai kabar bahwa Ia diutus ke dunia ini untuk menjalankan misi Allah dan misi tersebut harus digenapi dengan penderitaan yang begitu hebat. Disalibkan mati dan dikuburkan dan bangkit serta naik ke Sorga sebagai bukti bahwa Ia telah menjalankan misi Allah sampai tuntas. ${ }^{16}$ Berita ini juga memberikan kesan kepada murid-murid-Nya bahwa Ia harus mati di atas kayu salib dan melalui jalan itulah misi Allah tergenapi. Dengan kematian-Nya di atas kayu salib maka manusia yang telah berdosa dapat memperoleh keselamatan. Dengan demikian dalam menganalisis Injil Lukas dapat dipahami bahwa misi Yesus bersifat marturia yaitu memberitakan tentang kabar sukacita bahwa Allah mengasihi dunia ini dan mengutus anak-Nya untuk menggenapi misi Allah.

15 Enos, Penuntun Praktis Misiologi Modern, 78.

16 Tomatala, Teologi Misi, 58. 


\section{Misi Yesus Bersifat Koinonia}

Selain misi Yesus yang bersifat marturia, Lukas juga memperkenalkan misi Yesus dalam injilnya yang bersifat koinonia. Kata Yunani kolvwvı (koinonia) adalah kata benda feminim yang berasal dari akar kata: koıv (koine) dari kata dasar kolvoৎ (koinos) artinya bersekutu, mengambil bagian di dalam. ${ }^{17}$

Dari istilah di atas, koinonia memiliki makna bersekutu atau turut mengambil bagian di dalam penderitaan orang lain. Pada perkembangannya, kata ini sering digunakan dalam Perjanjian Baru dari Alkitab untuk menggambarkan hubungan dalam gereja Kristen mula-mula serta tindakan memecahkan roti (perjamuan kudus) sebagai tanda persekutuan dengan Kristus sekaligus peringatan untuk korban Kristus selama perjamuan Paskah (Yoh. 6: 48). Maka istilah koinonia digunakan di dalam Gereja Kristen dalam mewujudkan eksistensi jemaat yang saling mengasihi dan bersekutu bersama-sama. Dalam kaitanya dengan misi koinonia yang dilakukan oleh Yesus dalam konteks Injil Lukas, misiNya mencakup kaum marjinal yang terpinggirkan. Senior dan Stuhlmueller mengungkapkan bahwa pelayanan Yesus dalam konteks Injil Lukas merupakan praktik belas kasihan yang menerobos batas-batas antara individu dan kelompok. Konteks pelayanan misi Yesus adalah para pemungut cukai dan orang-orang Samaria yang tersisihkan. ${ }^{18}$ Yesus tidak menjadikan batasan sosial yang dilakukan oleh orang-orang Yahudi terhadap para pemungut cukai dan orang-orang Samaria sebagai satu alasan untuk tidak melayani mereka. Tetapi Yesus meruntuhkan tembok pemisah tersebut dan menjadikan mereka sebagai prioritas dalam misiNya. Lebih lanjut David J. Bosch mengungkapkan bahwa misi pelayanan Yesus

17 Sutanto, Perjanjian Baru Interlinear dan Konkordansi Jilid 1, 454.

18 Bosch, Transformasi Misi Kristen, 133. 
merupakan bentuk solidaritas dengan kaum miskin. ${ }^{19}$ Bentuk pelayanan Yesus tersebut merupakan misi yang bersifat koinonia. Contoh, Lukas 5: 27-32, Yesus makan bersama dengan Matius pemungut cukai dan teman-temannya. Pada saat itu orang-orang Farisi dan Ahli Taurat melihat Yesus yang makan bersama dengan orang-orang berdosa, mereka bersungut-sungut dan berkata, mengapa kamu makan dan minum bersama dengan orang-orang berdosa. Maka Yesus menjawab mereka katanya, Aku datang bukan untuk memanggil orang benar tetapi orang berdosa supaya mereka bertobat (Luk. 5: 32). ${ }^{20}$

Contoh lain dalam Injil Lukas 7: 36-50 dan Lukas 19: 1-10, Yesus diurapi oleh perempuan yang berdosa dan Zakheus. Yesus menumpang bersama di rumah Zakheus dan orang-orang melihat hal itu bersungut-sungut bahwa Yesus makan bersama dengan orang yang berdosa tetapi Yesus menjawab, Anak manusia datang untuk mencari dan menyelamatkan yang hilang. Pernyataan Yesus dalam menjawab orang-orang yang bersungut-sungut kepada-Nya secara eksplisit menunjukan bahwa misi-Nya bersifat koinonia. Misi yang menjangkau kaum marjinal seperti Matius, perempuan berdosa dan Zakheus pemungut cukai.

Berbeda dengan apa yang dilakukan oleh orang-orang Farisi dan ahli-ahli Taurat, mereka menciptakan sikap inklusif terhadap Zakheus dan Matius. Karena bagi mereka Zakheus dan Matius adalah orang-orang berdosa yang tidak layak untuk dikasihi. Secara status sosial para pemungut cukai memiliki status yang lebih rendah dimata orang-orang Farisi sehingga Matius dan Zakheus merupakan kaum marjinal yang tersisihkan. Namun Yesus menunjukan sikap yang kontras dengan apa yang dilakukan oleh orang-orang Farisi dan ahli-ahli Taurat. Ia 
menerima Zakheus dan makan bersama-sama dengan dia di rumahnya serta menjadikan Matius sebagai murid-Nya. Misi Yesus tersebut menunjukan bahwa misi-Nya bukan hanya bersifat marturia tetapi juga bersifat koinonia yaitu berkumpul bersama-sama dengan orang berdosa dan turut mengambil bagian dalam penderitaan yang mereka alami. Hal ini dilakukan Yesus dengan tujuan untuk untuk membawa mereka ke dalam Kerajaan Allah.

Misi Yesus ini melintasi seluruh tembok pemisah yang memisahkan antara orang-orang Yahudi dan kaum marjinal. Ia membuka pola pikir orang-orang Yahudi dan ahli-ahli Taurat bahwa misi-Nya adalah misi yang bersifat koinonia untuk menjangkau mereka yang tersisihkan.

\section{Misi Yesus Bersifat Diakonia}

Secara harafiah, kata diakonia berarti memberi pertolongan atau pelayanan. Dalam bahasa Ibrani kata penolong menggunakan kata ezer dalam Kejadian 2:18, Mazmur 121:1. Selain kata ezer kata diakonia dalam bahasa Ibrani juga menggunakan kata syeret yang artinya melayani. ${ }^{21}$ Dalam bahasa Yunani kata diakonia artinya pelayanan, diakonenin melayani. ${ }^{22}$

Dalam kebudayaan Yunani, kata diakonein memiliki arti yang luas cakupannya. Kata tersebut dapat merujuk kepada beberapa arti, yaitu: Pertama, diakonia berarti suatu pekerjaan yang hina sifatnya, yang hanya dilakukan budak. Kedua, diakonia adalah kewajiban para budak, yang harus dilakukannya tanpa pamrih. Itu berarti bahwa pelaku diakonia itu dituntut kesediaannya menanggung penderitaan demi pemuasan hati tuannya. Istilah diakonia ini ditemukan dalam zaman Perjanjian Lama secara kusus untuk kebudayaan timur tengah yang masih

21 Sabda: Software Alkitab, Biblika dan Alat-alat, versi 4.30, CD ROM, King James Version, 2013.

22 Hasan Sutanto, Perjanjian Baru Interlinear dan Konkordansi Jilid 2 (Jakarta: LAI, 2010), 463. 
menganut sistem tuan dan hamba. Seorang hamba bertanggung jawab untuk melayani tuannya. Maka istilah diakonia tidak familiar dalam konteks Timur Tengah. Dalam Perjanjian Baru istilah diakonia juga diberikan kepada tujuh orang diaken untuk melayani janda-janda miskin. Pelayanan yang dilakukan adalah memberikan bantuan kepada janda-janda agar mereka berkecukupan dalam kebutuhan sehari-hari.

Maka dalam mengkaji istilah diakonia berdasarkan konteks Perjanjian Lama dan Perjanjian Baru maknanya adalah melayani dan pelayanan tersebut hanya dilakukan oleh seorang hamba kepada tuannya. Dalam kaitanya dengan misi Yesus, Lukas juga memperkenalkan pelayanan-Nya bersifat diakonia. Misi ini juga dikenal dengan misi yang bersifat inklusif yaitu melayani mereka yang tidak terlayani. Pelayanan Yesus ini meliputi mereka yang lumpuh, buta, tuli, bisu, kerasukan roh jahat, membangkitkan orang yang mati, bahkan orang kerasukan roh jahat di Gerasa. Misi diakonia Yesus tersebut menunjukan bahwa pelayanan-Nya benar-benar bersifat hamba. Itulah sebabnya dalam Injil Lukas, Yesus diperkenalkan sebagai hamba Allah yang datang untuk melayani dan bukan untuk dilayani. David J. Bosch mengungkapkan bahwa pemerintahan Allah (basileia tou theou) adalah pusat pelayanan Yesus. ${ }^{23}$ Sehingga fokus dan tujuan Yesus terarah dengan jelas. Jiwa-jiwa yang tersesat dan terabaikan itulah yang dilayani-Nya. Dalam hal ini orang-orang kaya dan ahli Taurat bukan dilalaikan oleh Yesus tetapi dalam konteks Injil Lukas Yesus melihat kaum marjinal sebagai prioritas utama.

23 Bosch, Transformasi Misi Kristen, 48. 
Misi dalam perspektif pemerintahan Allah mencakup tindakan membuat orang-orang yang miskin, terabaikan dan dibenci bangkit kembali sebagi orang yang dipulihkan kemanusiaan mereka yang penuh dihadapan Allah dan manusia. Dalam hal ini mengangkat moral orang-orang yang terabaikan menjadi mulia di hadapan-Nya. Dengan demikian dalam menganalis misi Yesus dalam Injil Lukas maka dapat dipahami bahwa orientasi dalam pelayanan Yesus adalah menjalankan misi Allah. Paradigma misi Yesus bukan untuk penanaman gereja melainkan menjalankan isi hati Bapa bagi dunia ini.

\section{Aplikasi Misi Inklusif Yesus Dalam Konteks Misi Masa Kini.}

Dengan mengamati misi Yesus dalam Injil Lukas maka dapat dipahami bahwa misi Yesus adalah misio Dei yaitu melayani kaum marjinal yang diabaikan. Yesus melayani mereka tanpa melihat bagaimana status mereka, orientasi pelayanan Yesus hanya berpusat pada misi Allah bagi dunia ini. Oleh karena itu, dalam menganalisis misi masa kini yang hanya berorientasi pada penanaman gereja maka perlu untuk melihat pada misi Inklusif Yesus sebagai contoh dalam melakukan misi gereja. Maka hal ini bisa terwujud apabila adanya transformasi misi masa kini secara agar kembali kepada esensi dari misio Dei atau misi yang diamanatkan Tuhan.

Adapun beberapa langkah yang perlu dilakukan sebagai transformasi misi masa kini atara lain sebagai berikut:

\section{Transformasi Hakekat Misi}

Tranformasi berasal dari bahasa Latin transformare artinya perpindahan dari satu tempat ketempat yang lain. Dengan demikian transformasi dapat dipahami sebagai perubahan dan pembaharuan dari bentuk yang lama ke bentuk 
yang baru. ${ }^{24}$ Berkaitan dengan tranformasi misi maka transformasi berarti perubahan misi antroposentris kepada misio Dei atau misi Allah. Hakekat misi yang agung dan mulia yang diamanatkan Tuhan bagi murid-murid-Nya yang esensinya adalah menjalankan misi Allah. Maka dalam mengamati dan menganalisa misi masa kini yang berorientasi pada misi untuk pertumbuhan gereja secara kuntitas perlu untuk ditransformasikan agar kembali kepada hakekat misi yang sesungguhnya. Misi gereja haruslah memberitakan tentang kabar baik bahwa Yesus telah menebus manusia dari dosa dan melalui Dia semua yang percaya pasti akan selamat. Misi gereja seharusnya mencakup misi inklusif Yesus yaitu bersaksi, bersekutu dan melayani kaum marjinal. Orientasi gereja harus mencakup isi hati Allah bagi dunia ini yaitu menyampaikan kabar keselamatan yang datang dari Tuhan. Transformasi ini bisa terwujud apabila gereja menyadari bahwa gereja adalah alat Tuhan untuk menyampaikan kabar sukacita bagi dunia.

Seni inilah yang hilang dalam gereja masa kini dalam menjalankan misi. Gereja lebih fokus pada pertumbuhan secara kuantitas, jemaat yang banyak menjadi fokus utama tanpa memperhatikan apakah metode yang dilakukan untuk memenangkan jiwa sudah sesuai dengan kehendak Tuhan. Segala upaya yang dilakukan adalah untuk pertumbuhan gereja semata. Maka misi yang dilakukan pun motivasinya adalah penanaman gereja. Setiap jiwa yang dimenangkan harus menjadi anggota baru dalam gereja.

Oleh karena itu penting sekali gereja masa kini menyadari esensi dari misi dan kembali kepada dasar misi yang diamanatkan Tuhan yaitu membawa jiwa-

24 Theodorus Kobong, Iman Dan Kebudayaan (Jakarta: BPK Gunung Mulia, 1994), 31. 
jiwa untuk kemuliaan Tuhan. Dalam hal ini bukan berarti melalaikan esensi gereja sebagai umat Allah yang membawa shalom ke dalam dunia ini.

Yakob Tomatala mengungkapkan bahwa gereja harus berpartisipasi dalam rencana restorasi Allah yaitu berpartisipasi dalam misi-Nya untuk keselamatan dunia. ${ }^{25}$ Maka sangat penting gereja mengambil bagian dalam melakukan misi. Dalam kaitannya pekerjaan gereja atau misi harus fokus kepada menjadi alat bagi manusia untuk memperoleh keselamatan dari Allah yang membawa restorasi di dalam diri setiap orang. Maka sikap gereja dalam menyikapi hal ini adalah memberitakan Injil kerajaan Allah sebagai wujud mitra Allah. Namun yang perlu disadari dari gereja dalam mengemban tugas misi tersebut adalah memperhatikan hakekat misi sehingga misi yang dilakukan adalah untuk kemuliaan Tuhan.

\section{Transformasi Motivasi}

Selain transformasi hakekat misi, transformasi untuk motivasi misi masa kini penting untuk dilakukan sebagai upaya untuk mewujudkan kembali misio Dei dalam gereja. David J. Bosch Mengungkapkan bahwa krisis misi masa kini terletak pada motif, sasaran dan hakikat. ${ }^{26}$ Krisis yang dimaksudkan dalam misi masa kini adalah motivasi misi adalah untuk penanaman gereja. Dalam hal ini orientasi misi bukan misi Allah tetapi misi yang bersifat anthroposentris untuk kepentingan gereja.

Sangat ironis, apabila mengakaji misi masa kini, Allah bukan satu-satunya yang menjadi tujuan dalam melakukan misi tetapi kepentingan pribadi. Itulah sebabnya apabila misi sekarang ini dibandingkan dengan misi Yesus untuk 
diaplikasikan dalam konteks pelayanan maka misi sekarang perlu untuk ditransformasi.

Yakob Tomatala dalam bukunya mengungkapkan bahwa esensi dari motivasi misi yang agung memiliki kebenaran sebagai berikut: ${ }^{27}$ Pertama, Motif misi Allah adalah kasih. Motivasi ini didasarkan atas kebenaran bahwa Allah memberi Anak-Nya dan menyelamatkan manusia berdosa karena kasih. Kedua, Motif misi Allah adalah motif yang urgen. Motif yang urgen ini terfokus pada keselamatan segenap manusia karena keselamatan orang berdosa adalah laksana utang yang harus dibayar. Motivasi misi tersebut di atas harus menjadi sikap pelaksana misi yang perlu dihayati oleh gereja sebagai dasar bagi pelaksana misi.

Orlando E Costas, dalam bukunya yang berjudul, The Integriti of Mision, mengungkapkan ada tiga hal yang menjadi integritas dalam misi yaitu: Pertama, proclaiming God's name, Kedua, proclaiming God's kingdom, Ketiga, proclaiming God's moment. ${ }^{28}$ Memproklamasikan nama Tuhan berarti memberitakan bahwa Allah itu kasih dan Ia telah mengaruniakan Anak-Nya ke dalam dunia dan telah mati untuk menebus manusia sehingga setiap orang yang percaya dan menerima-Nya pasti selamat. Sedangkan memproklamirkan kerajaan Allah adalah memberitakan kepada orang lain bahwa apabila mereka percaya kepada anak Allah akan diselamatkan dan mereka akan menjadi ahli waris kerajaan Allah dan kerajaan Allah sudah dekat waktunya. Demikian sama halnya dengan pemberitaan Yohanes Pembaptis bahwa mereka harus bertobat dan menerima kerajan Allah. 
Ketiga hal tersebut seharusnya menjadi motivasi utama dalam pelayanan misi masa kini. Tidak peduli apakah jiwa yang dimenangkan akan menjadi anggota dalam gereja atau tidak fokus dan arah misi harus memberitakan tentang nama Yesus, Kerajaan Allah harus ditinggikan dan memberitakan kabar sukacita yang datang dari Tuhan tanpa adanya motivasi untuk kepentingan pribadi.

\section{KESIMPULAN}

Berdasarkan uraian di atas dapat disimpulkan bahwa esensi dari misi adalah memberitakan Kabar Baik kepada orang lain agar mereka percaya dan diselamatkan. Atau dengan kata lain misi adalah menjalankan misio Dei yang diamanatkan Tuhan. Orientasi pelayanan misi haruslah menjalankan misi agung yang telah dilakukan oleh Yesus bukan misi untuk pertumbuhan gereja semata. Misi inklusif yang bersifat marturia, kainonia, diakonia perlu diterapkan sehingga esensi misi untuk kemuliaan nama Tuhan. Soli Deo Gloria.

\section{DAFTAR PUSTAKA}

Boland, B.J. Tafsiran Lukas. Jakarta: BPK Gunung Mulia, 1970.

Bosch, David J. Transformasi Misi Kristen. Jakarta: BPK Gunung Mulia, 2008.

Costas, Orlando E. The Integrity of Mision. New York: Harper and Row Publisher, 1999.

Enos, I Nyoman. Penuntun Praktis Misiologi Modern. Bandung: Kalam Hidup, 2003.

Injil Lukas. Jakarta: LAI, 1990.

Kobong, Theodorus. Iman Dan Kebudayaan. Jakarta: BPK Gunung Mulia, 1994.

N, N. "Kunci Bagi Pertumbuhan Gereja Sesudah Dirintis." Www.misi.sabda.org. $\begin{array}{llll}\text { E-Misi. } & \text { Diakses } & 15 & \text { Februari }\end{array}$ https://misi.sabda.org/enam_kunci_bagi_pertumbuhan_gereja_sesudah_dir intis. 
Sabda: Software Alkitab, Biblika dan Alat-alat (versi 4.30). CD ROM. King James Version, 2013.

Surtjantoro, Bagus. Misi Dari Dalam Krisis. Jakarta: Obor Mitra Indonesia, 2003.

Sutanto, Hasan. Perjanjian Baru Interlinear dan Konkordansi Jilid 1. Jakarta: LAI, 2010. 108.

—. Perjanjian Baru Interlinear dan Konkordansi Jilid 2. Jakarta: LAI, 2010. 585.

Tomatala, Yakub. Teologi Misi. Jakarta: Leadership Foundation, 2003.

Wagner, Peter. Penanaman Gereja Untuk Tuaian Yang Lebih Besar. Jakarta: Harvest Publication House, 1995. 